\title{
Biocompatibility of Plastic Clip in Neurocranium - Experimental Study on Dogs
}

\author{
Samir DELIBEGOVIC ${ }^{1,2}$, Kemal DIZDAREVIC $^{3}$, Elmir CICKUSIC ${ }^{2,4}$, Muhamed KATICA ${ }^{5}$, Muamer OBHODJAS ${ }^{5}$, \\ Muhamed OCUS ${ }^{6}$
}

\author{
${ }^{1}$ University Clinical Center Tuzla, Department of Surgery, Bosnia and Herzegovina \\ ${ }^{2}$ University of Tuzla, Faculty of Medicine, Bosnia and Herzegovina \\ ${ }^{3}$ University Medical Center of University of Sarajevo, Neurosurgery Clinic, Bosnia and Herzegovina \\ ${ }^{4}$ University Clinical Center Tuzla, Laboratory Diagnostics Polyclinic, Bosnia and Herzegovina \\ ${ }^{5}$ University of Sarajevo, Veterinary Faculty, Bosnia and Herzegovina \\ ${ }^{6}$ Private Veterinary Ambulance, Uravici, Visoko, Bosnia and Herzegovina
}

\section{ABSTRACT}

AIM: A potential advantage of the use of the plastic clips in neurosurgery is their property of causing fewer artifacts than titanium clips as assessed by computed tomography and magnetic resonance scans. The biocompatibility of plastic clips was demonstrated in the peritoneal cavity, but their behavior in the neurocranium is not known.

MATERIAL and METHODS: Twelve aggressive stray dogs designated for euthanasia were taken for this experimental study. The animals were divided into two groups. In all cases, after anesthesia, a craniotomy was performed, and after opening the dura, a proximal part titanium clip was placed on the isolated superficial Sylvian vein (a permanent Yasargil FT $746 \mathrm{~T}$ clip at a $90^{\circ}$ angle, while a plastic Hem-o-lok clip ML was placed on another part of the vein). The first group of animals was sacrificed on the $7^{\text {th }}$ postoperative day and the second group on the $60^{\text {th }}$ postoperative day. Samples of tissue around the clips were taken for a histopathological evaluation.

RESULTS: The plastic clip caused a more intensive tissue reaction than the titanium clip on the $7^{\text {th }}$ postoperative day, but there was no statistical difference. Even on the $60^{\text {th }}$ postoperative day there was no significant difference in tissue reaction between the titanium and plastic clips.

CONCLUSION: These preliminary results confirm the possibility for the use of plastic clips in neurosurgery. Before their use in human neurosurgery, further studies are needed to investigate the long-term effects of the presence of plastic clips in the neurocranium, as well as studies of the aneurysmal model.

KEYWORDS: Titanium clips, Plastic clips, Biocompatibility, Neurocranium, Dog

\section{INTRODUCTION}

$\mathrm{T}$ The fourth generation of clips used in neurosurgery are made of either titanium or its alloy, which decreases artifacts on computed tomography (CT) and magnetic resonance (MR) scans (8). The physical properties of plastic materials enable the plastic clips to cause less artifacts than titanium clips, which is their potential advantage (4).
The biocompatibility of plastic clips in the peritoneal cavity (5) has been confirmed, but their behaviour in the neurocranium is unknown. For this reason, we undertook the prospective experimental study, in which we compared the biocompatibility of titanium and plastic clips placed in the neurocranium. 


\section{MATERIAL and METHODS}

The study was started after approval was obtained from the Ethics Committee of the Veterinary Faculty, the University of Sarajevo. Twelve dogs, weighing from 10 to $15 \mathrm{~kg}$, acclimatized to standard laboratory conditions, were placed in cages (the temperature inside was from $20-24^{\circ} \mathrm{C}$ with 12 hour light/dark cycle). The dogs were randomized into two groups. Those in group I had their clips kept in until the seventh postoperative day. The dogs in group II had the clips in place until the $60^{\text {th }}$ postoperative day.

\section{Preoperative Preparation of Dogs}

Stray dogs that exhibited aggressive and overexcited behavior towards the local community of Uvorići, Visoko, and presented a real danger to the general population and other domestic animals, were designated to be removed and euthanized by the Cantonal Veterinary Inspection, in accordance with the Law on Animal Welfare in Bosnia and Herzegovina.

The dogs that were prepared for the operative procedure were crossbreeds, approximately 10 years old (their age was determined by the examination of their teeth on the mandible and maxilla), male, weighing about $15 \mathrm{~kg} \pm 3.5$, had a normal constitution and habitus, and, appeared clinically healthy. Two days before the operative procedure, the dogs were treated with anti-helminthic for ecto- and endoparasites.

\section{Protocol for Induction of General Anesthesia}

The act of premedication was performed by the application of Meloxicam at a dose of $0.2 \mathrm{mg} / \mathrm{kg}$ of the body weight intramuscularly, after which iv. cannula was placed in the right vein brachiocephalic.

Afterwards, each dog underwent anesthesia; the induction process required for the application of $70 \%$ of the dose $(1.05$ $\mathrm{ml}$ ) of anesthetic, ketamine-xylazine in a ratio of $50 \%: 50 \%$. Ketamine was applied at a dose of $5 \mathrm{mg} / \mathrm{kg}$ of the body weight; its concentration of $100 \mathrm{mg} / \mathrm{ml}$, xylazine in dose $1 \mathrm{mg} /$ $\mathrm{kg}$ of the body weight was $2 \%$ of the concentration.

To maintain anesthesia of the dogs, $20 \%$ of the same dose was used; i.e. $0.3 \mathrm{ml}$ of ketamine-xylazine, in the abovementioned ratio.

After placing the endotracheal tube (ET tube size 8.0) and esophageal probe, the values of the pulse and breathing were measured and recorded into the anesthesia protocol. The values of these parameters were recorded every five minutes all the way through the end of the operative procedure, i.e. the extubation of the subject.

\section{Surgical Procedure}

Preparation of the operative field: hairs on the head in the right parietal region were removed mechanically, the area was then shaved and the preparation for the operative field was performed with chlorhexidine, and afterwards, with $10 \%$ of povidone iodine. $4 \mathrm{ml}$ of $2 \%$ lidocaine chydrochloride with adrenaline was applied locally to the place of incision. During the operative procedure, saline fluid at a dose of $10 \mathrm{ml} / \mathrm{kg} / \mathrm{hr}$ was administered intravenously.
After administering a local anesthetic with diluted adrenaline (Figure 1), a right fronto-temporal incision of the skin was made. An arc incision was made from the front sagittal line all to way to the left ear. Afterwards, additional infiltration was done by cutting the temporal fascia and muscle and the denudation of muscles from the bones of the temporofrontal area bellow the deep fascia. Part of a muscle was taken to serve as the autologous graft during the closing of the wound. A trepanation hole was made by a manual perforator in the temporal area, followed by a fronto-temporal craniectomy, which was done using the Kerrison tongs. The intact dura above the frontal and right temporal lobe of brain was noticed. Then, an incision of the dura took place, after which the superficial Sylvian vein showed up and permanent, titanium Yasargil FT 746 T clips were placed (blade length $7.0 \mathrm{~mm}$, external size $19.5 \mathrm{~mm}$, weight $0.2 \mathrm{~g}$, closing force $1.96 \mathrm{~N}$ ) on the proximal end at an angle of $90^{\circ}$ while a plastic Hem-olok ML clips was placed (external size $9.3 \mathrm{~mm}$, weight 0.05 g) on the distal end (Figure 2). In order to reduce the liquor leakage, the integrity of arachnoid mater had to be preserved. Hemostasis was made by washing it out with saline, a local hemostatic, mild compression and wax. The dura was not closed by direct sutures, rather, it was placed back into its original position over of brain, and then the piece of muscle was placed over the dura in order to maintain the protection of the brain and clips, which decreased the possibility of an eventual cerebrospinal fluid leak. This was followed by sutures of the muscles, fascia and skin by a continuous 2-0 suture.

Possible local and systemic complications were monitored during the observational period. After this procedure, on the seventh/sixtieth postoperative day, a craniectomy is performed again, and the clip with the sample of surrounding tissue was collected.

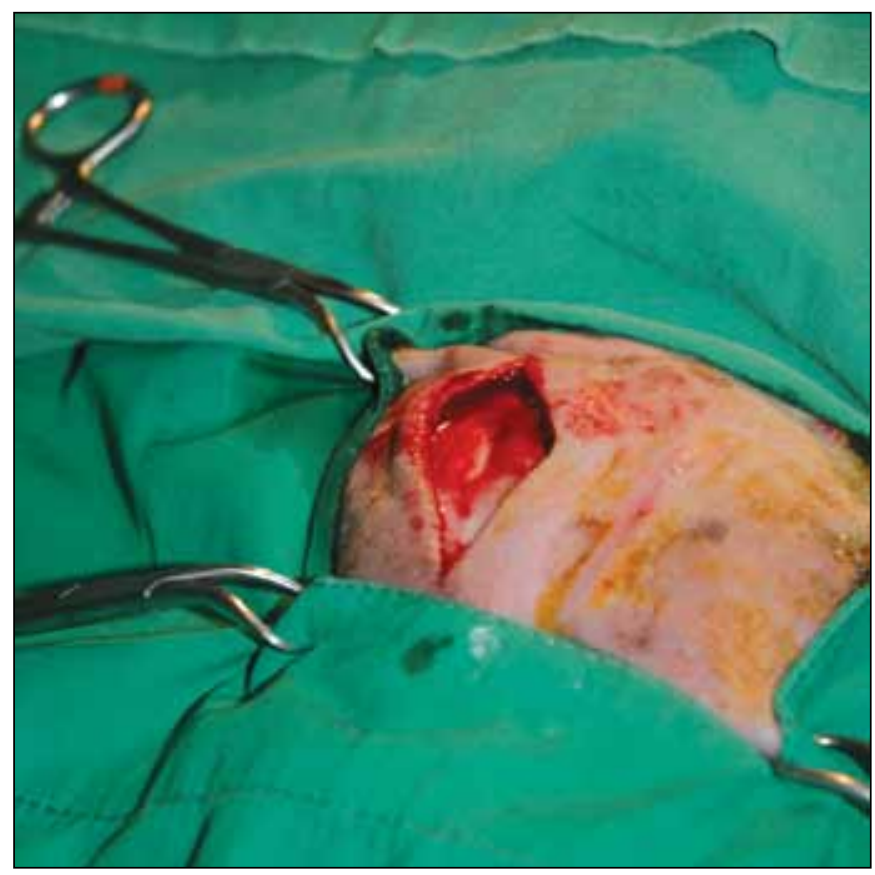

Figure 1: Incision on the dog's scalp. 


\section{Euthanasia}

After placing an i.v. cannula into the brachiocephalic vein, the general anesthetic was applied, which was a combination of ketamine-xylazine (the same dose as during the anesthesia).

After the first measure of pulse and breathing was completed and it was established that they were within physiological limits, the T61 drug (embutramide $200 \mathrm{mg} / \mathrm{ml}$, mebezonium iodide $50 \mathrm{mg} / \mathrm{ml}$ and tetracaine hydro-chloride $5 \mathrm{mg} / \mathrm{ml}$ ) was applied at a dose from 0.3 to $0.5 \mathrm{ml} / \mathrm{kg}$ body weight. Failure of the vital functions of the heart and lungs was confirmed after 5 minutes.

\section{Histopathological Procedure}

The biopsy material was formalin-fixed, cut into standard 5-mm slices, and colored by application according to the standard procedure for H\&E (hematoxylin eosin) staining. Microscopic analysis was performed with an Olympus BX41 microscope. The tissue sample from around the titanium and plastic clip was analyzed. Tissue reaction was graded as mild, moderate and severe.

\section{Statistical Analysis}

The Fisher exact probability test was used for analysis of differences between distributions of histopathological changes. Differences were considered significant for $p<0.05$.

\section{RESULTS}

All the dogs that we operated on had a $100 \%$ survival rate and

Table I: Histopathological Findings on the $7^{\text {th }}$ Postoperative Day

\begin{tabular}{lcc}
\hline Degree of inflammation & Titanium clip & Plastic clip \\
\hline Mild & 1 & \\
\hline Moderate & 2 & 1 \\
\hline Severe & 3 & 5 \\
\hline
\end{tabular}

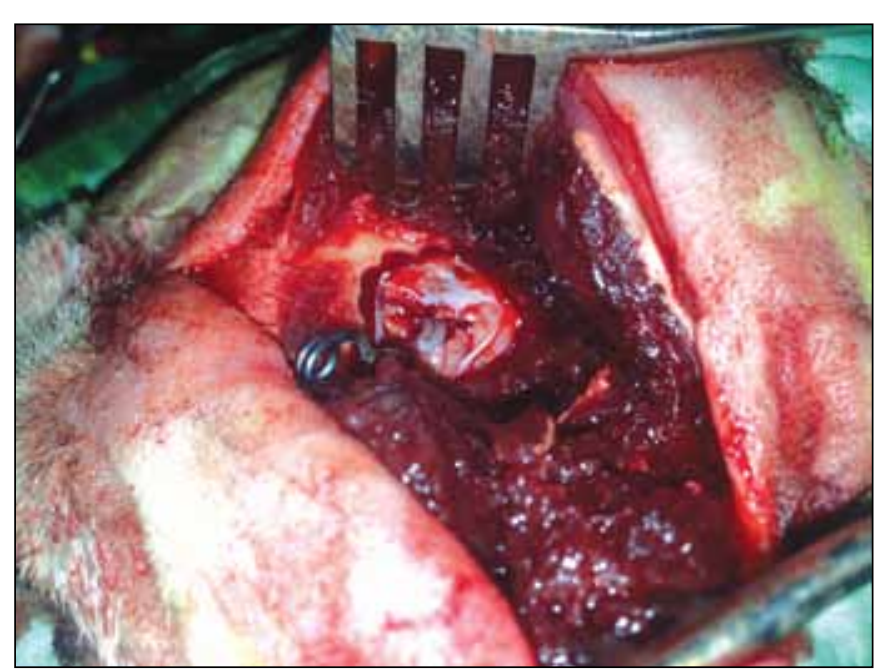

Figure 2: The placed permanent titanium clip and Hemolok ML plastic clip. were able to return to normal food and water intake. No other complications were observed.

The tissue reaction in the field just around the clips was analyzed. Under a light microscope, on the seventh postoperative day, in groups of plastic clip ( $\mathrm{P}-1)$ severe inflammation dominated (Table I), especially lymphocytes, histiocytes and rare polymorphonuclear leukocytes compared to the titanium clip that caused a moderate inflammatory response of the same composition (Figures 3, 4).

The Fisher exact probability test did not identify any statistically significant differences in the degree of mild $(p=1)$, and moderate $(p=1)$ inflammation and severe inflammation $(p=0.545)$ after the application of the titanium and plastic clips on the $7^{\text {th }}$ postoperative day.

On the sixtieth postoperative day, in the groups with the titanium clip, moderate inflammation was present (Table II), but

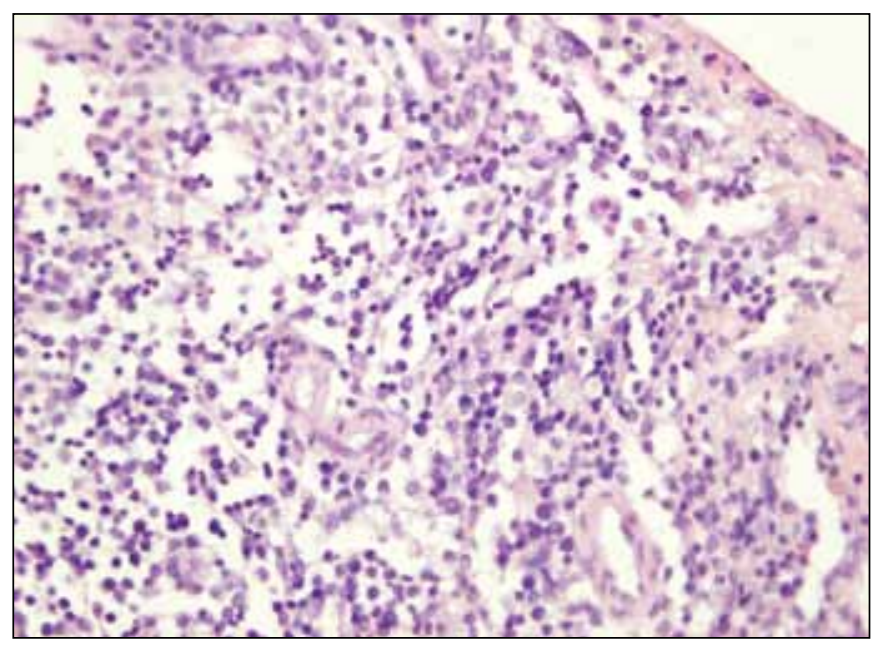

Figure 3: Severe inflammatory reaction of the neutrophils, histiocytes and lymphocytes developed on the titanium clip on the $7^{\text {th }}$ postoperative day (H\&E, 400X).

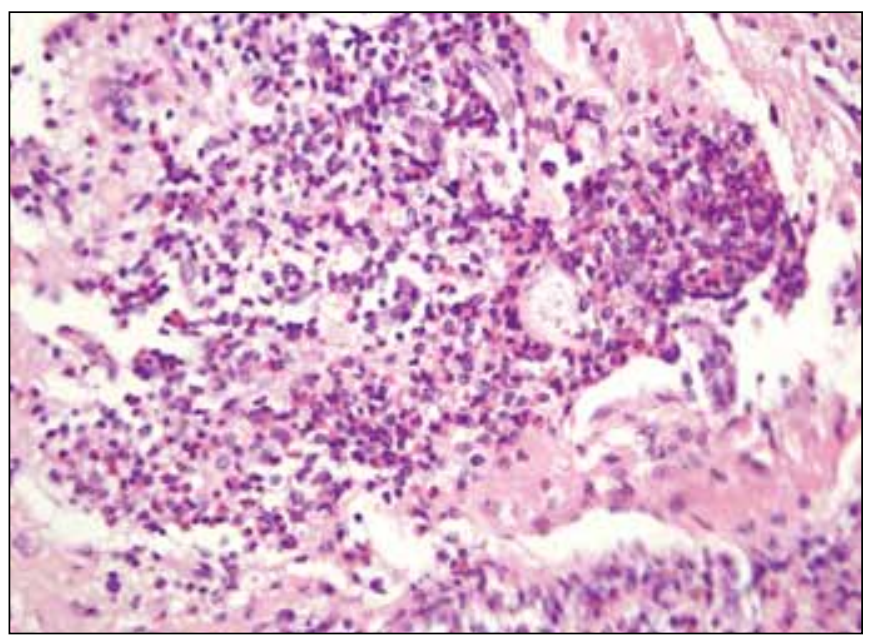

Figure 4: Severe inflammatory reaction of neutrophils, and numerous eosinophils, lymphocytes and rare histiocytes developed on the plastic clips on the $7^{\text {th }}$ postoperative day (H\&E, 400X). 
the Fisher exact probability test did not identify any statistically significant differences in the degrees of mild $(p=1)$, moderate $(p=0.567)$ inflammation and severe inflammation $(p=s)$ after the application of the titanium and plastic clips on the $60^{\text {th }}$ postoperative day (Figures 5,6 ).

\section{DISCUSSION}

The fourth generation of clips used in neurosurgery are made of titanium and its alloy (8). It is known that titanium causes a mild inflammatory reaction. Plastic clips have a potential advantage of use in the neurocranium (4), but there are no published studies so far investigating the effects of the plastic clip in the neurocranium, although the use of hem-o-lok clips, which are nonabsorbable, polymer structures for ligation of vessels, ureters, bile ducts and the base of appendix, has been documented in over 1,000 surgical procedures in the abdomen $(6,7,9-11)$.

On the seventh postoperative day, in the groups with plastic clips, severe inflammation dominated, but there was no statistical significance in relation to the titanium clips. Generally, peak inflammatory reactions on foreign bodies occurred on the seventh postoperative day (1). However, neither on the $60^{\text {th }}$ postoperative day, was there any significant difference in the inflammation between the titanium and plastic clips.

The size of the plastic clip was smaller (permanent Yaşargil FT 746 T clip, blade length $7.0 \mathrm{~mm}$, external size $19.5 \mathrm{~mm}$, weight $0.2 \mathrm{~g}$, plastic Hem-o-lok clip ML external size $9.3 \mathrm{~mm}$, weight

Table II: Histopathological Findings on the $60^{\text {th }}$ Postoperative Day

\begin{tabular}{lcc}
\hline Degree of inflammation & Titanium clip & Plastic clip \\
\hline Mild & 1 & 2 \\
\hline Moderate & 4 & 2 \\
\hline Severe & 1 & 2 \\
\hline
\end{tabular}

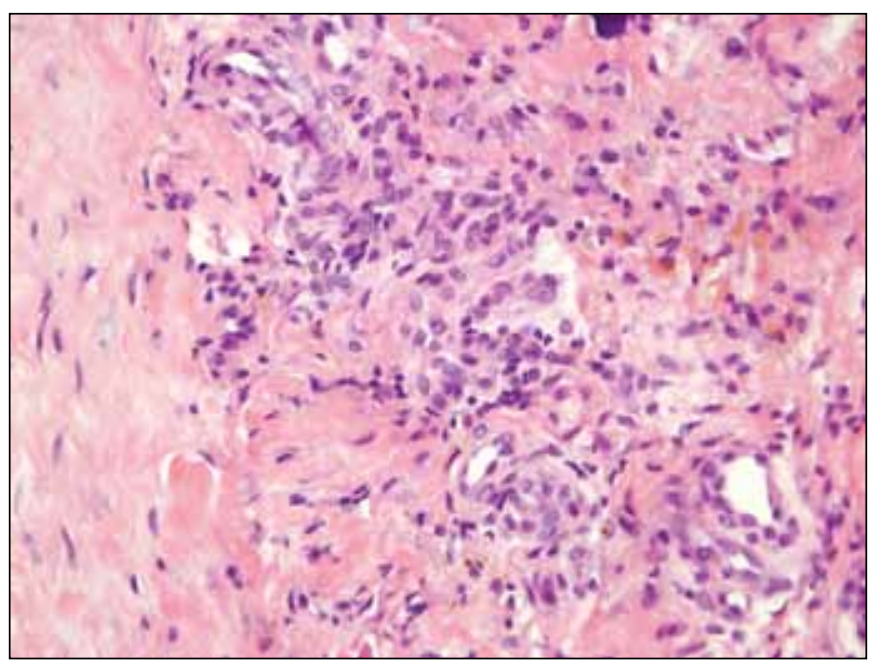

Figure 5: Moderate inflammatory reaction of lymphocytes, histiocytes and fibrosis developed on the titanium clip on the $60^{\text {th }}$ postoperative day (H\&E, 400X).
$0.05 \mathrm{~g}$ ) than that of the titanium clip because it had a part which went to the applier; this part was missing in the plastic clip. Generally, these are some of the advantages of plastic also because the reduction in the inflammatory response correlates directly to a reduction in size of the implanted material (3).

The closing force of Yaşargil FT 746 T clips is $1.96 \mathrm{~N}$, while the manufacturer of Hem-o-lok clips does not mention their closing force. But their clinical use e.g. for renal hilum ligation during laparoscopic nephrectomy (2), is proof that their closing force is sufficient to stop the bloodstream.

It is important to emphasize that the price of the Yaşargil FT 746 clip used in this experimental study was 184.47 Euros, but the price of a Hem-o-lok MI clip is drastically lower, only 4.75 Euros.

Limitations of this study were the sample size, which was too small for definitive conclusions to be drawn, but the clinical use of plastic clips and other studies of its biocompatibility in the abdomen (3), demonstrated its biocompatibility. However, it is important to emphasize that this is the first study to investigate the effects of plastic clips in neurocranium, which may open up a new avenue of research with direct therapeutic value.

A small difference in the inflammation between the titanium clip, which is the standard in neurosurgery, and the plastic clip, demonstrates the possibility of the potential use of plastic clip in neurosurgery. We believe that in the near future neurosurgeons will use plastic clips during surgical procedures for cerebral aneurysm, because of their radiological advantages (they cause less artifacts), mechanical properties (lower weight) and lower price.

Further studies of the mechanical properties of plastic clips and studies of the aneurysmal model, will be an introduction to their final use in human neurosurgery.

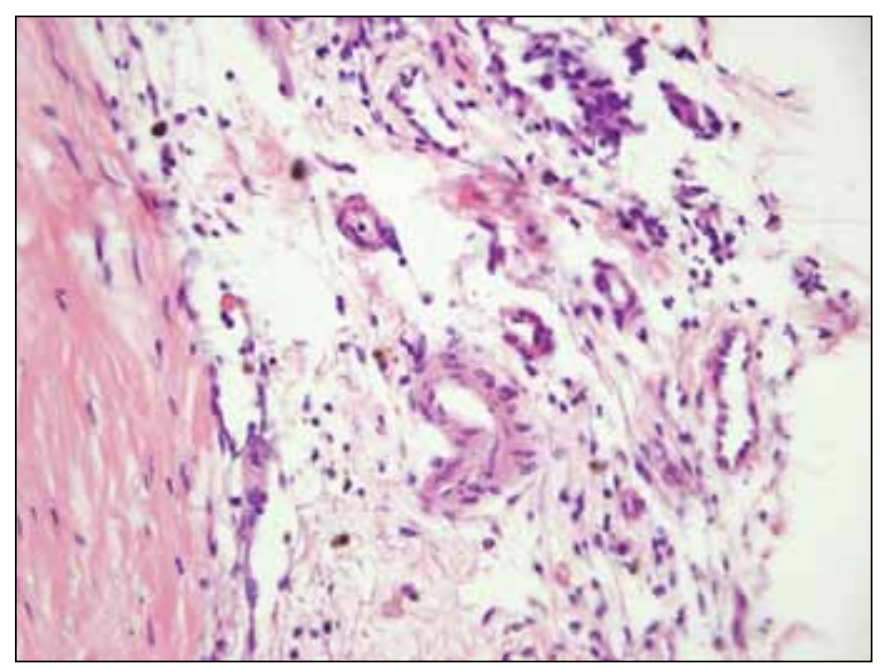

Figure 6: Moderate inflammatory reaction of lymphocytes and histiocytes developed on the plastic clip on the $60^{\text {th }}$ postoperative day (H\&E, 400X). 


\section{REFERENCES}

1. Baptista, ML, Bonsack ME, Felemovicius I, Delaney JP: Abdominal adhesions to prosthetic mesh evaluated by laparoscopy and electron microscopy. J Am Coll Surg 190:271-280, 2000

2. Bomfim AC, Andreoni C, Miotto A, Araujo MB, Ortiz V, Poli de Figureido LF, Srougi M: The "Boatmans knot": A new option for renal hilum ligation during laparoscopic nephrectomy. Acta Cir Bras 20:744-749, 2005

3. Cobb WS, Kercher KW, Heniford BT: The argument for lightweight polypropylene mesh in hernia repair. Surg Innv 12:63-69, 2005

4. Delibegovic S. Radiologic advantages of potential use of polymer clips in Neurosurgery. World Neurosurg 81:549-551, 2014

5. Delibegovic $\mathrm{S}$, Iljazovic $\mathrm{E}$, Katica $\mathrm{M}$, Koluh $\mathrm{A}$ : Tissue reaction to absorbable endoloop, nonabsorbable titanium staples, and polymer Hem-o-lok clip after laparoscopic appendectomy. JSLS 15:70-76, 2011

6. Delibegović S, Matović E: Hem-o-lok plastic clips in securing of the base of the appendix during laparoscopic appendectomy. Surg Endosc 23:2851-2854, 2009
7. Delibegovic S: The use of a single Hem-o-lok Clip in securing the base of the appendix during laparoscopic appendectomy. J Laparoendosc Adv Surg Tech A 22:85-87, 2012

8. Kakizawa Y, Seguchi T, Horiuchi T, Hongo K: Cerebral aneurysm clips in the 3-tesla magnetic field. Laboratory investigation. J Neurosurg 113:859-869, 2010

9. Pradeep B, Anant K, Aneesh S, Devendra K, Anil M, Mahendra B: Laparoscopic radical nephrectomy; our initial experience. Indian J Urol 20:154-159, 2004

10. Schick KS, Hutti TP, Fertmann JM, Hurnung KM, Jauch KW, Hofmann JN: A critical analysis of laparoscopic appendectomy: How experience with 1.400 appendectomies allowed innovative treatment to become standard in a University Hospital. World $J$ Surg 14:289-293, 2008

11. Tobias-Machado $M$, Forseto $P$, Medina J, Watanabe $M$, Juliano $\mathrm{R}$, Wroclawski E: Laparoscopic radical prostatectomy by extraperitoneal access with duplication of the open technique. Int Braz J Urol 30:55-60, 2004 